\title{
AiMT
}

Advances in Military Technology

Vol. 13, No. 2 (2018), pp. 141-156

ISSN 1802-2308, eISSN 2533-4123

DOI 10.3849/aimt.01239

\section{Statistics of Ejections in Military Jet Aircraft in Czechoslovakia and the Czech Republic}

\author{
O. Zavila* \\ Department of Fire Protection, Technical University of Ostrava, Czech Republic
}

The manuscript was received on 14 March 2018 and was accepted after revision for publication on 15 May 2018.

\begin{abstract}
:
The article deals with the statistics of aviation accidents associated with the ejection of the crew in military jet fighter, fighter-trainer and trainer aircraft in the service of Czechoslovakia and the Czech Republic from 1948 until the end of 2016. It presents a unique, previously unpublished comprehensive overview of aviation accidents (disasters, air crashes and damage) in which the crew ejected, as well as a critical analysis of types of events involved, date of their origin, type and version of the aircraft and also the number of killed and rescued crew members. The figures are accompanied by numerous annotations and an overview of still accessible reference and information sources on the subject.
\end{abstract}

\section{Keywords:}

Army of the Czech Republic, Czechoslovak People's Army, ejection, aviation accident, jet fighter, statistics

\section{Introduction}

Two basic questions were the reasons for this study: "How dangerous was and is the military jet flying for an aircraft crew?" and "What chance to survive does the crew have in a situation when it is no longer possible to complete the planned flight and to land safely?" The solution to this problem lies in the ability of the crew to abandon the aircraft in time and to land on the ground using another means (parachute). Under certain conditions it is possible to abandon even a military jet aircraft by simply jumping from the cockpit. These are, however, very rare situations in which the interplay of coincidences, knowledge, piloting skills and good fortune gives rise to circumstances that enable sustaining life of the crew. In the history of Czechoslovakia and the Czech Republic such occurrences have been very scarce.

\footnotetext{
"Corresponding author: Department of Fire Protection, VSB - Technical University of Ostrava, Lumírova 13/630, CZ-700 30 Ostrava, Czech Republic. Tel.: +420 597322 893, E-mail: ondrej.zavila@vsb.cz
} 
Due to the altitude and airspeed of military jet aircraft, in the vast majority of cases, the only und ultimate option for the crew to save their lives is ejection. In spite of the technical advancements in aircraft rescue systems and current training possibilities for aircraft crews, in many ways it is important to build on historical experience (especially concerning the role of the human factor). How the crews of different types of aircraft at different times were successful in rescuing themselves in emergency situations is discussed in the following paragraphs. Scope and Available Information Sources

This study deals with the statistics of aviation accidents (hereinafter "AA") of military jet fighters, fighter-trainers and trainers in Czechoslovakia and the Czech Republic in 1948-2016 focusing on cases of ejection of one or more crew members.

For the purposes of the following statistical overviews, ejection means the procedure of an emergency exit of the aircraft by the crew using the ejection seat from the moment the ejection seat completely leaves the cockpit. Situations where the procedure was commenced, but the ejection seat failed to leave the cockpit and the crew member was killed, were not included in the statistics. Two cases with such characteristics are known to the author: disasters in MiG-23 U (in 1996) and L-159 (in 2003).

Cases in which the cockpits of the investigated types of jets were abandoned in flight by the crew jumping out, i.e. without using the ejection seat due to its malfunction, are not included either. Two cases with such characteristics are known to the author: air crashes in MiG-19 S (1959) and MiG-15 SB (1964).

The information sources for the compilation of the following overviews can be divided into five groups.

The first group of information sources includes the aviation literature of fact by Miroslav Irra [1-7] and Libor Režňák [8, 9] based on expert interpretation of the sources mainly from the Central Military Archives of Prague [10] that deal with military aviation accidents in the former Czechoslovakia. The information obtained there was suitably supplemented by a personal correspondence and consultations with the authors. These sources cover the period approximately from 1948 to 1960.

The second group of information sources covers the period from 1960 to 1984. It includes primarily a five-volume staff manual for the Czechoslovak People's Army Air Forces [11-15]. It offers a comprehensive overview of AAs for the periods concerned, accompanied by explanations, reflections and statistical analyses. It was issued as crucial classified internal material of the then Czechoslovak People's Army to reinforce prevention of aviation accidents.

The third group of information sources covers the period 1985-2016. The data is saved in the database of the military Integrated System for Logistics (hereinafter "ISL") [16] that allows searching and filtering events by selected criteria.

The fourth and most important group of information sources are the original investigation reports of AAs found in the Central Military Archives in Prague [10] and particularly in the Administrative Archives of the Armed Forces of the Czech Republic in Olomouc [17]. The original investigation reports could be found to more than two-thirds of the 209 investigated accidents.

The fifth and most interesting group of information sources were the testimonies of 20 surviving direct AA participants (ejected pilots) who, with their comments and often still vivid memories, helped to interpret and complement some of the contents of the investigation reports. 
In summary, the most difficult to find today is the information about aviation accidents associated with ejections that took place in the 1950s and early 1960s.

\section{Classification of Aviation Accidents}

The classification of AAs used in the following five pictures (see Fig. 1-5) and one table (see Tab. 1) is based on the contents of the Všeob-P-10 Flight Safety regulation [18], which was in force between 2006 and June 2016, being replaced by the Order of the Minister of Defence No. 13/2016 Journal - Flight Safety of $15^{\text {th }}$ June 2016 [19]. In this Order of the Minister of Defence, however, substantial changes in definitions, terminology and classification of emergency occurrences in military aviation were made. Therefore, in order to effectively synchronize data from AAs for different periods, the author of this study chose to use the classification system based on the previous Všeob-P-10 Flight Safety regulation. Most of available technical literature and archival records are based on the contents of this Všeob-P-10 Flight Safety regulation, including the information base from the Information System for Logistics [16], a part of which has been used by the Air Forces of the Army of the Czech Republic (hereinafter "AF ACR") to keep records of emergency occurrences since 1985 to the present day.

According to the Všeob-P-10 Flight Safety regulation, aviation accident was defined as the designation for the consequences of the degree of an air traffic occurrence in which:

a) The crew members or passengers were killed or seriously injured except when the death or injury was from natural causes, self-inflicted or inflicted by other persons.

b) The aircraft was destroyed, damaged or there was a malfunction that required major repair or replacement of main airframe parts.

There were three types of AAs: disaster, air crash and damage. Disaster was an AA in which lives were lost among the crew members or passengers. Air crash was an AA in which the aircraft was totally destroyed or irreversibly lost with non-fatal consequences for the flight crew and passengers or damaged to such an extent that a repair would not be possible or practical. Damage was an AA in which the flight crew members or passengers were not fatally or seriously injured, but the aircraft was damaged to such an extent that the aircraft or its main airframe part had to be handed over for repair outside the military unit or a repair team, called to the military unit specifically for this purpose, had to carry out the repair [18].

\section{Statistical overviews}

The following statistical overviews list the number of disasters (see Fig. 1) and air crashes (see Fig. 2) associated with tshe ejection of one or more aircraft crew members in 1948-2016. They are followed by a list of number of aircraft crew members killed after ejection (see Fig. 3).

The overviews are presented on a timeline, broken down by aircraft types and accompanied by totals of AAs or disaster victims for different aircraft types in each year. In the bottom left corner, the total sum of AAs of given type (see Fig. 1 and Fig. 2) or of killed aircraft crew members (see Fig. 3) is shown. Numbers in brackets represent the number of AAs associated with the ejection of one or several crew 


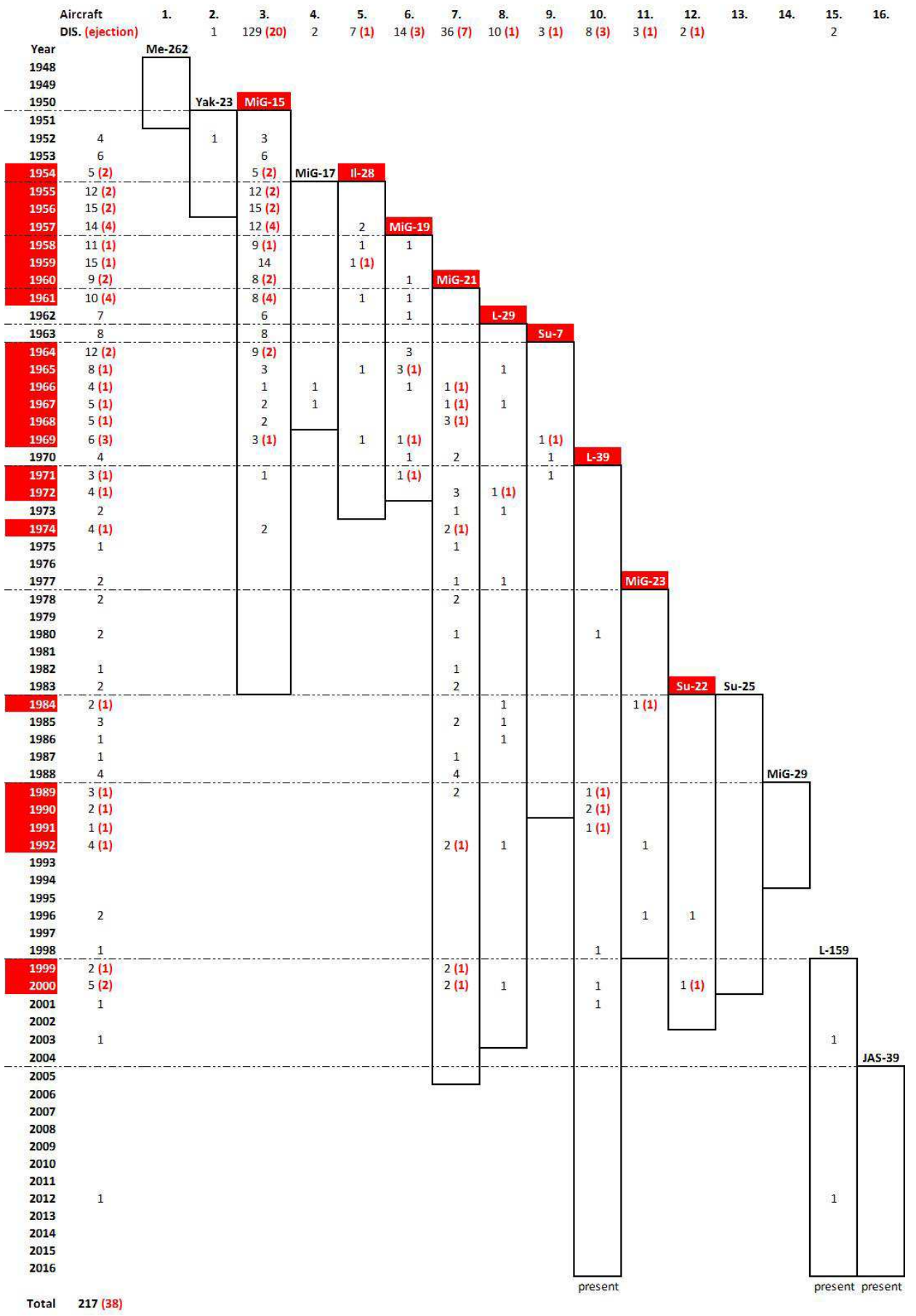

Number of Aircraft $\quad 10$ pcs 12 pcs 1547 pcs 26 pcs 77 pcs 185 pcs 476 pcs 204 pcs 104 pcs 72 pcs 70 pcs 58 pcs 36 pcs 20 pcs 72 pcs 14 pcs

Fig. 1 Disasters associated with the ejection of aircraft crews in 1948-2016 [1-17] 


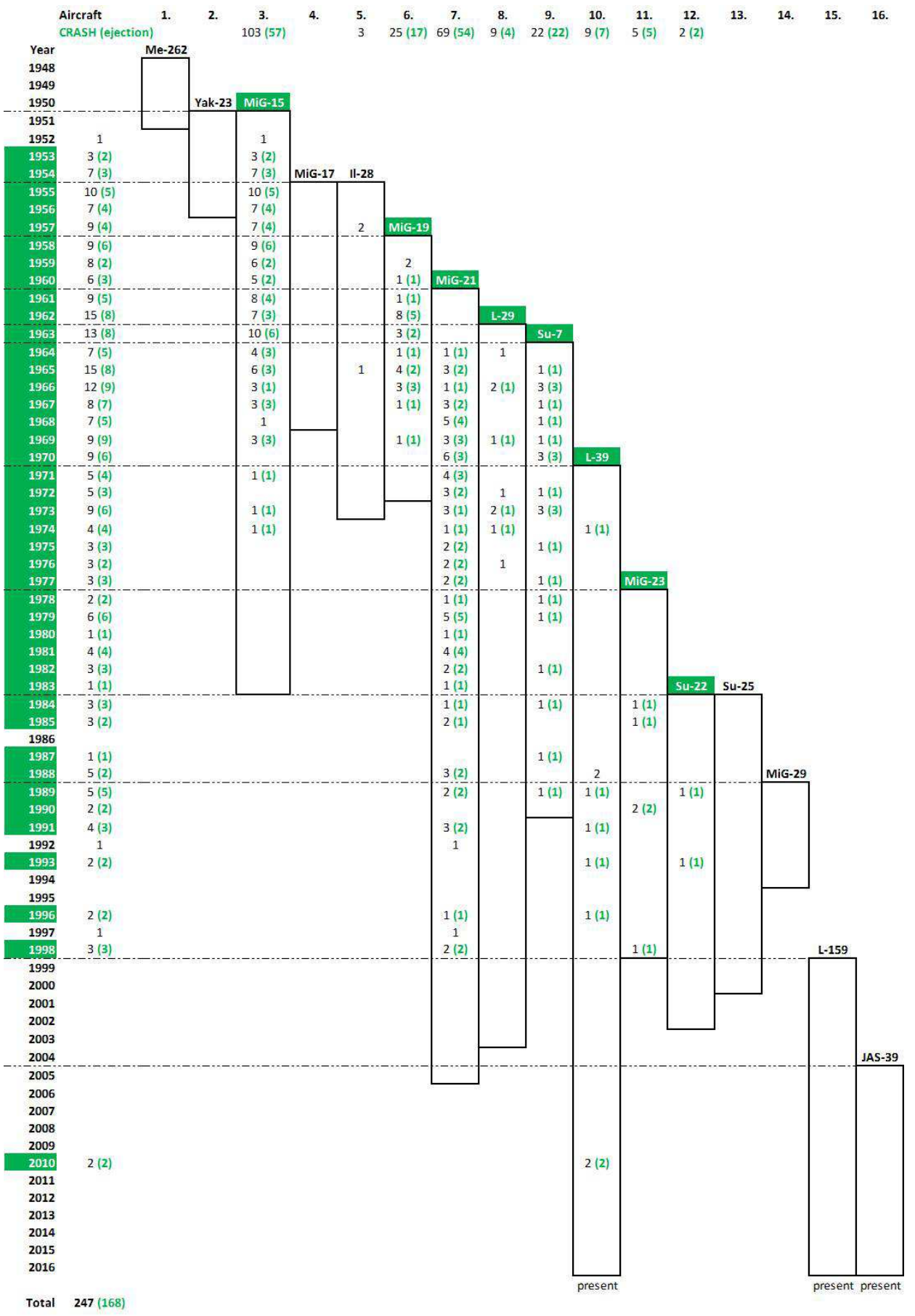

Number of Aircraft $\quad 10$ pcs 12 pcs 1547 pcs 26 pcs 77 pcs 185 pcs 476 pcs 204 pcs 104 pcs 72 pcs 70 pcs 58 pcs 36 pcs 20 pcs 72 pcs $\quad 14$ pcs

Fig. 2 Air crashes associated with the ejection of aircraft crews in 1948-2016 [1-17] 


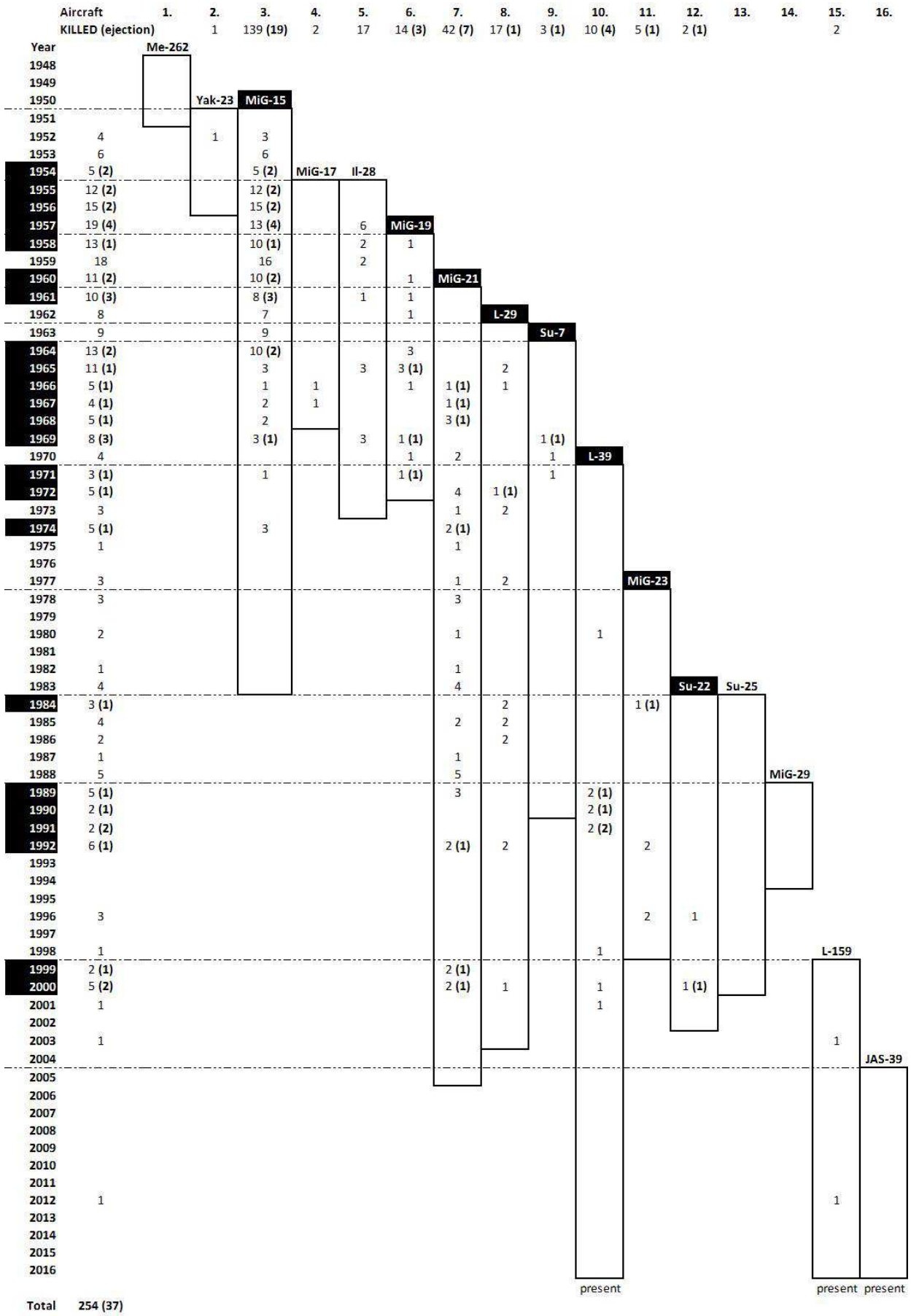

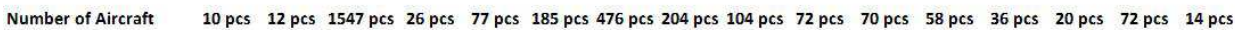

Fig. 3 Number of victims of unsuccessful ejections of aircraft crews in 1948-2016 [1-17] 
members (see Fig. 1 and Fig. 2) or the number of unsuccessfully ejected (killed) crew members for each type of aircraft in different years (see Fig. 3).

The figures also show in what order different types of aircraft were introduced into active service, the duration of their service and their total number. The colored fields indicate the types of aircraft in which the ejections occurred and the relevant period.

\section{Interesting Facts, Contexts and Development Trends}

Over the past 68 years' history of military jet aviation in Czechoslovakia and the Czech Republic, there were a total of 209 AAs associated with the ejection of one or more crew members, representing $32.3 \%$ of the total number of 647 recorded and traceable accidents (the sum of disasters, crashes and damage events).

The total of 235 aircraft crew members directly participated in these emergency occurrences. Most of them (234 crew members) were flight staff members; only one was a non-flight staff member. Among the flight staff there were also 3 foreign student pilots.

The total of 228 ejections took place in the above mentioned AAs, out of which 37 were unsuccessful (the crew members were killed) and 191 successful (the crew members survived). From the remaining 7 pilots that did not eject, four never even attempted to do so and were killed. The remaining 3 crew members did not need to attempt ejection because they managed to land the damaged plane ( 3 cases of damage - see Fig. 3). The following sections provide more detailed analyses of the statistics.

\subsection{Analysis of Ejections by AA Types over Time}

For the formulation of development trends over time regarding AAs associated with aircraft crew ejections, the graphical (see Fig. 1 to Fig. 4) and tabular (Tab. 1) overviews provide the following facts.

AAs recorded as disasters associated with the aircraft crew ejection accounted for $17.5 \%$ of all recorded disasters and their number decreased over time (see Fig. 1 and Fig. 4). The greatest number of such disasters was recorded from the second half of the 1950 s to the beginning of the 1970s. The most critical years were 1957 (4 disasters) and 1961 (4 disasters). The last disaster of this kind was recorded in 2000.

AAs recorded as air crashes associated with aircraft crew ejections accounted for full $68 \%$ of all recorded disasters and their number also decreased over time (see Fig. 2 and Fig. 4), but at a much slower pace than in the case of disasters. The largest number of these events was recorded from the second half of the 1950s to the end of 1980s. The most critical years were 1966 (9 air crashes) and 1969 (9 air crashes). The last air crash of this kind was recorded in 2010.

If we put into a ratio the number of disasters ( 38 disasters) with the number of air crashes (168 air crashes) of that kind, we observe that air crashes clearly predominated with the ratio of more than $4: 1$.

It can be explained by a relatively high reliability of on-board rescue systems (ejection seats) if they were, such as in most cases, used in a timely matter, correctly and in line with their technical capabilities of the time. In only 2 cases of AAs recorded as disasters, in the MiG-15 T in 1964 and the Su-7 BM in 1969, the pilots were killed in the ejection or its aftermath due to a proven failure of the on-board rescue system. 


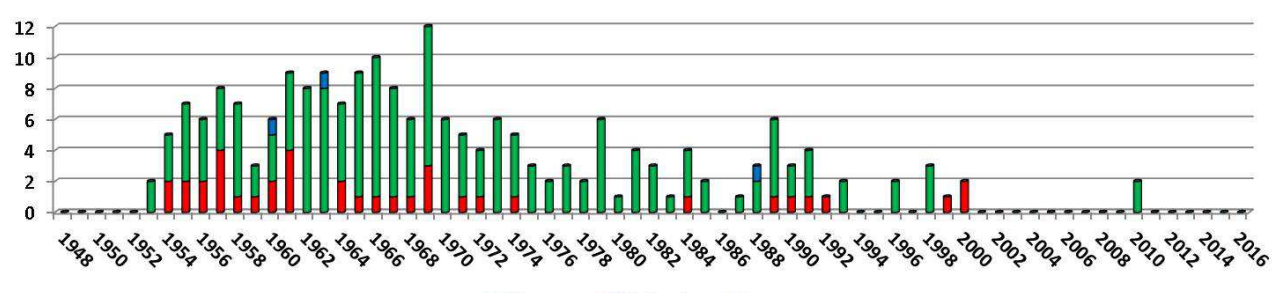

$\square$ Disasters $\square$ Air Crashes $\square$ Damage
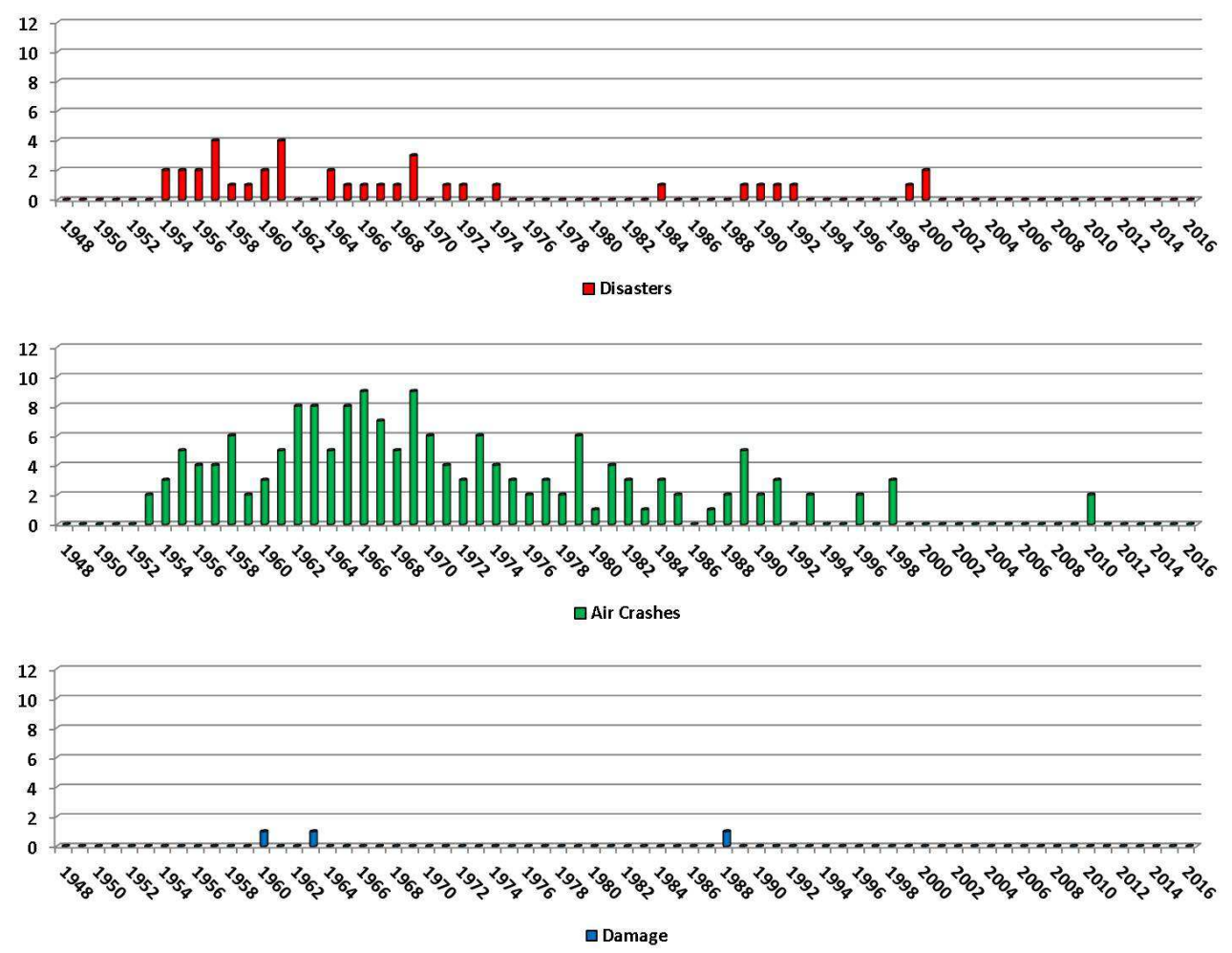

Fig. 4 Graphical overview of total and partial numerical representation of individual types of AAs associated with aircraft crew ejections in 1948-2016 [1-17]

AAs recorded as damage associated with aircraft crew ejections accounted for only $1.6 \%$ of all recorded damage accidents and their occurrence can be considered entirely exceptional (see Fig. 4). They were recorded only in 1960 (1 damage accident), 1963 ( 1 damage accident) and 1988 (1 damage accident). In the first two cases it was the UTI MiG-15 and in the third case it was the L-39 C.

\subsection{Analysis of Ejections by Aircraft Types}

In general, there are two ways to objectively assess the flight safety for different aircraft types. In the context of this study, they can be referred to as "exact evaluation" and "framework evaluation".

The exact evaluation would relate three values: the total number of flight hours for a given aircraft type in a given year, the number of aircraft of a given type in active 
service in a given year and the number of relevant AAs for a given aircraft type in a given year. Hereby, we would obtain the number of hours flown between individual AAs in different types of aircraft for the year concerned. If such a calculation were performed for each year in chronological order, we would get a basis for a tabular or graphical representation of flight safety trends across aircraft types and time periods in accordance with then applicable regulations for the classification of AAs.

The framework evaluation uses calculations of average values for the variables of interest throughout the investigated period. However, their interpretation must be supplemented by an explanation of logical links resulting from the country's technical and even political developments contexts. This gives rise to the formulation of development trends which is based on the interpretation of time-averaged values of the observed parameters.

To assess the flight safety in different types of aircraft from the statistics of ejections, for the most part, the framework assessment had to be used. For the exact assessment, the necessary data are usually not available anymore, especially those regarding the number of flight hours for different aircraft types in a given year and the number of aircraft of a given type in active service in a given year.

Let us choose the following five basic sets of information for the framework assessment of safety for each type of aircraft:

1) Predestination of individual types of aircraft;

2) Total number of individual aircraft types (see Fig. 1 to Fig. 3).

3) Total number of years of active service for each type of aircraft (see Fig. 1 to Fig. 3).

4) Total number of AAs per type of aircraft where the life of the crew was threatened, i.e. the sum of disasters and air crashes (see Fig. 1 to Fig. 3 and Tab. 1).

5) Total number of ejections in each type of aircraft (see Tab. 1).

If these groups of information were analyzed and linked to one another, the following facts related to flight safety could be inferred.

The predestination of different types of aircraft characterizes the primary purpose for which they were designed. This purpose varied from type to type and also had its own history. To a great extent, it also determined the level of risk to the crew. There were single-purpose and multi-purpose aircraft. The single-purpose aircraft included the fighter (Me-262, Yak-23, MiG-15, MiG-17, MiG-19, MiG-21, MiG-23 and MiG-29), bomber (Il-28) and attack (Su-25) aircraft. The multi-purpose aircraft included the fighter-bomber (Su-22), bomber-attack (Su-7), trainer-reconnaissance (L-29), trainer-fighter-attack (L-39 and L-159) and fighter-attack-reconnaissance (JAS-39) aircraft. The highest safety risks are in fighter aircraft (especially in supersonic fighters) as they operate in the widest ranges of altitudes, speed and flight modes; thus, the possibilities for the generation of in-flight emergencies caused by technical failures, human errors or environmental factors are wide-ranged. The general trend in the military aviation of Czechoslovakia and the Czech Republic has been the reduction in the original use of single-purpose aircraft in favor of multi-purpose aircraft.

The total number of individual aircraft types also varied considerably from 10 (the Me-262) to 1547 (the MiG-15). In terms of flight safety, it is not without interest that AAs were very scarce, or even non-existent, in aircraft of high interest operating in low numbers (e.g. Me-262, Yak-23, Mig-17 or later Mig-29, L-159, JAS-39) or in aircraft originally delivered as single seaters (e.g. Su-25). This can be explained by an 
increased attention in both maintenance and operation, as well as by being piloted by crews with a higher standard of training or with more experience.

The total number of years of service of an aircraft ranged from 4 (Me-262) to 47 (L-39) so far. Overlapping service periods of individual types in the context of their predetermination indicate, among other things, the extent of preparedness of the military air force for a real armed conflict at different times. For example, in 19641968 seven types of military jet aircraft were operated simultaneously in high numbers in Czechoslovakia; in 1989-1990 there were even 8 types of military jet aircraft of various predestinations, albeit in much smaller numbers. This was reflected in the accident rates in those periods. The higher is the number of simultaneously operated aircraft types, and also their flight hours, the more likely is the occurrence of incidents or directly AAs.

The highest number of AAs in which the life of the crew was threatened (the sum of disasters and air crashes) was recorded in the MiG-15 (232 AAs), MiG-21 (105 AAs) and MiG-19 (39 AAs). These figures alone, however, may not necessarily reflect the level of safety of those aircraft types. The number of AAs must be contextualized with at least the total number of operated aircraft, the total number of years of their active service and also with their predestination, i.e. with the mode of their operation.

If we put into a ratio the numbers of individual aircraft types with the number of AAs in which the life of the crew was threatened, we obtain the number of aircraft of a given type per one AA associated with a life-threatening situation to the crew. The most unfavorable results were found for the Su-7 and L-39 (1 AA per 4.2 aircraft), Mig-21 (1 AA per 4.5 aircraft) and MiG-19 (1 AA per 4.7 aircraft). Thus, it can be said that an AA associated with a life threat to the crew occurred in every fourth to fifth aircraft of those types.

If we put into a ratio the total numbers of individual aircraft types with the total numbers of ejections (both successful and unsuccessful) in these aircraft types, we obtain the number of aircraft of a given type per one ejection. The most unfavorable results were found for the L-39 (1 ejection per 4.2 aircraft), Su-7 (1 ejection per 4.3 aircraft), MiG-21 (1 ejection per 7.4 aircraft) and MiG-19 (1 ejection per 9.3 aircraft). These figures, however, cannot be considered as an indicator of level of safety for individual aircraft types, but rather as an indicator of the crew training standards. Even an unsuccessful ejection attempt shows that the crew responded to the in-flight incident. The more of such responses, the higher the probability of a successful rescue.

In sum, this numerical statistics does not allow an evaluation of which aircraft type was the most dangerous for its crew; it only shows in which type of aircraft there were the highest number of AAs of the kind. As far as the numerical evaluation is concerned, it might seem that the MiG-15 and MiG-21 were indisputably the most dangerous aircraft types for the crew; in fact, all we can only say is these types of aircraft were those with the highest number of AAs, which can be easily explained by their predestination (jet fighters) and, even more importantly, by how many of them there were in active service. Even more AAs per the number of aircraft of a given type were recorded, for example, for the Su-7 and L-39. An important fact is that the operation of most aircraft was a risk for the crew only during a certain period of time. If an aircraft had been operated at other times, i.e. at a different quality level of air navigation systems or meteorological services and with crews with different training, it would certainly have been reflected in its AA statistics. The task of statistics is only to direct an analyst to the interest groups of subjects to be further analyzed, not to draw resolute conclusions. 


\subsection{Analysis of Ejections by the Number of Killed and Rescued Crew Members}

For the objective assessment of flight safety in each type of aircraft in terms of the number of killed and rescued crew members, the framework assessment was used again (see Section 4.2 above). Let us choose five basic sets of information again:

1) Total number of individual aircraft types (see Fig. 1 to Fig. 3).

2) Total number of years of active service for each type of aircraft (see Fig. 1 to Fig. 3).

3) Total number of victims of AAs for each type of aircraft (see Fig. 3 and Tab. 1).

4) Total number of unsuccessfully ejected (killed) crew members in AAs for each type of aircraft (see Fig. 3 and Tab. 1).

5) Total number of successfully ejected (rescued) crew members in AAs for each type of aircraft (see Tab. 1).

If these groups of information were analyzed and linked to one another, the following facts related to flight safety could be inferred.

If we put into a ratio the total number of years of active service of individual aircraft types with the total number of killed crew members in these aircraft types, we obtain the number of killed crew members per one year of active service for a given type of aircraft. The most unfavorable results were found for the MiG-15 (approx. 4 killed crew members per year), MiG-21 (approx. 1 killed crew member per year) and Il-28 and MiG-19 (1 killed crew member per one year and one month). It should be noted that most of these cases of loss of life occurred in 1950s and 1960s when there was not much experience with jet flying and many problems were faced, especially those involving technical and human factors that would be addressed in the following years. Also, in those two decades the highest number of jet aircraft (over 1,000 of various types) in the history of both Czechoslovak and Czech military aviation was in operation.

If we put into a ratio the total numbers of individual aircraft types and the total number of killed crew members in each of these aircraft types, we obtain the number of aircraft per 1 lost life of a crew member. The most unfavorable results were found for the Il-28 (1 victim per approx. 5 aircraft), L-39 (1 victim per approx. 7 aircraft) and MiG-15 (1 victim per approx. 11 aircraft).

In terms of total number of victims of AAs associated with ejection, the MiG-15 was ranked first with the total of 19 victims (basic version - 11 victims, bis version 5 victims, SB, T and UTI versions -1 victim each). The MiG-21 was ranked second with the total of 7 victims (F-13 version -3 victims, PF, MF, MFN and UM versions 1 victim each). The L-39 was ranked third with the total of 4 victims (ZA version -3 victims, $\mathrm{C}$ version -1 victim).

In terms of total number of crew members rescued in AAs associated with ejection, the MiG-15 was also ranked first with the total of 68 rescued crew members (basic version - 23 rescued, UTI version - 18 rescued, bis version - 15 rescued, etc.).

The MiG-21 was ranked second with the total of 57 rescued crew members (F-13 version -21 rescued, MF version - 9 rescued, PF and PFM versions -7 rescued each, etc.). The Su-7 was ranked third with the total of 23 rescued crew members (BM version -14 rescued, BKL version -7 rescued and $U$ version -2 rescued).

In general, the ejection in AAs was not a matter of course. The number of attempts to eject gradually increased and so did their success rate (see Fig. 5). The first successful ejection attempt took place in 1953, e.g. not until two years after the 
Tab. 1 Number of AAs and number of ejected aircraft crew members in 1948-2016 (sorted by aircraft types and number of AAs / number of ejected crew members) [1-17]

\begin{tabular}{|c|c|c|c|c|c|c|c|}
\hline \multirow{2}{*}{$\begin{array}{l}\text { Aircraft type } \\
\text { and version }\end{array}$} & \multicolumn{4}{|c|}{ Number of AAs (ejections) } & \multicolumn{3}{|c|}{ Number of ejected crew members } \\
\hline & Disaster & Air crash & Damage & Total & Killed & Rescued & Total \\
\hline \multicolumn{8}{|l|}{ MiG-15 } \\
\hline MiG-15 & 11 & 23 & 0 & 34 & 11 & 23 & 34 \\
\hline MiG-15 bis & 5 & 15 & 0 & 20 & 5 & 15 & 20 \\
\hline MiG-15 SB & 1 & 3 & 0 & 4 & 1 & 3 & 4 \\
\hline MiG-15 bis SB & 0 & 2 & 0 & 2 & 0 & 2 & 2 \\
\hline MiG-15 bis $\mathrm{R}$ & 0 & 7 & 0 & 7 & 0 & 7 & 7 \\
\hline MiG-15 T & 1 & 0 & 0 & 1 & 1 & 0 & 1 \\
\hline UTI MiG-15 & 2 & 7 & 2 & 11 & 1 & 18 & 19 \\
\hline $\begin{array}{c}\text { Total for } \\
\text { aircraft type }\end{array}$ & $\begin{array}{c}20 \\
(25.3 \%) \\
\end{array}$ & $\begin{array}{c}57 \\
(72.2 \%) \\
\end{array}$ & $\begin{array}{c}2 \\
(2.5 \%) \\
\end{array}$ & $\begin{array}{c}79 \\
(100 \%) \\
\end{array}$ & $\begin{array}{c}19 \\
(21.8 \%) \\
\end{array}$ & $\begin{array}{c}68 \\
(78.2 \%) \\
\end{array}$ & $\begin{array}{c}87 \\
(100 \%) \\
\end{array}$ \\
\hline \multicolumn{8}{|l|}{ MiG-21 } \\
\hline MiG-21 F-13 & 3 & 21 & 0 & 24 & 3 & 21 & 24 \\
\hline MiG-21 PF & 1 & 7 & 0 & 8 & 1 & 7 & 8 \\
\hline MiG-21 PFM & 0 & 7 & 0 & 7 & 0 & 7 & 7 \\
\hline MiG-21 R & 0 & 3 & 0 & 3 & 0 & 3 & 3 \\
\hline MiG-21 MA & 0 & 5 & 0 & 5 & 0 & 5 & 5 \\
\hline MiG-21 MF & 1 & 9 & 0 & 10 & 1 & 9 & 10 \\
\hline MiG-21 MFN & 1 & 0 & 0 & 1 & 1 & 0 & 1 \\
\hline MiG-21 UM & 1 & 2 & 0 & 3 & 1 & 5 & 6 \\
\hline $\begin{array}{c}\text { Total for } \\
\text { aircraft type }\end{array}$ & $\begin{array}{c}7 \\
(11.5 \%)\end{array}$ & $\begin{array}{c}54 \\
(88.5 \%)\end{array}$ & $\begin{array}{c}\mathbf{0} \\
(0 \%)\end{array}$ & $\begin{array}{c}61 \\
(100 \%)\end{array}$ & $\begin{array}{c}7 \\
(10.9 \%)\end{array}$ & $\begin{array}{c}57 \\
(89.1 \%)\end{array}$ & $\begin{array}{c}64 \\
(100 \%)\end{array}$ \\
\hline \multicolumn{8}{|l|}{$\mathrm{Su}-7$} \\
\hline Su-7 BM & 1 & 14 & 0 & 15 & 1 & 14 & 15 \\
\hline Su-7 BKL & 0 & 7 & 0 & 7 & 0 & 7 & 7 \\
\hline Su-7 U & 0 & 1 & 0 & 1 & 0 & 2 & 2 \\
\hline $\begin{array}{c}\text { Total for } \\
\text { aircraft type }\end{array}$ & $\begin{array}{c}1 \\
(4.3 \%)\end{array}$ & $\begin{array}{c}22 \\
(95.7 \%)\end{array}$ & $\begin{array}{c}0 \\
(0 \%)\end{array}$ & $\begin{array}{c}23 \\
(100 \%)\end{array}$ & $\begin{array}{c}1 \\
(4.2 \%)\end{array}$ & $\begin{array}{c}23 \\
(95.8 \%)\end{array}$ & $\begin{array}{c}24 \\
(100 \%)\end{array}$ \\
\hline \multicolumn{8}{|l|}{ MiG-19 } \\
\hline MiG-19 S & 3 & 11 & 0 & 14 & 3 & 11 & 14 \\
\hline MiG-19 P & 0 & 1 & 0 & 1 & 0 & 1 & 1 \\
\hline MiG-19 PM & 0 & 5 & 0 & 5 & 0 & 5 & 5 \\
\hline $\begin{array}{c}\text { Total for } \\
\text { aircraft type }\end{array}$ & $\begin{array}{c}3 \\
(15.0 \%) \\
\end{array}$ & $\begin{array}{c}17 \\
(85.0 \%) \\
\end{array}$ & $\begin{array}{c}0 \\
(0 \%) \\
\end{array}$ & $\begin{array}{c}20 \\
(100 \%) \\
\end{array}$ & $\begin{array}{c}3 \\
(15.0 \%) \\
\end{array}$ & $\begin{array}{c}17 \\
(85.0 \%) \\
\end{array}$ & $\begin{array}{c}20 \\
(100 \%) \\
\end{array}$ \\
\hline \multicolumn{8}{|l|}{ L-39 } \\
\hline L-39 C & 1 & 5 & 1 & 7 & 1 & 9 & 10 \\
\hline L-39 ZA & 2 & 2 & 0 & 4 & 3 & 4 & 7 \\
\hline $\begin{array}{c}\text { Total for } \\
\text { aircraft type }\end{array}$ & $\begin{array}{c}3 \\
(27.3 \%)\end{array}$ & $\begin{array}{c}7 \\
(63.6 \%)\end{array}$ & $\begin{array}{c}1 \\
(9.1 \%)\end{array}$ & $\begin{array}{c}11 \\
(100 \%)\end{array}$ & $\begin{array}{c}4 \\
(23.5 \%)\end{array}$ & $\begin{array}{c}13 \\
(76.5 \%)\end{array}$ & $\begin{array}{c}17 \\
(100 \%)\end{array}$ \\
\hline \multicolumn{8}{|l|}{ MiG-23 } \\
\hline MiG-23 BN & 1 & 3 & 0 & 4 & 1 & 3 & 4 \\
\hline MiG-23 MF & 0 & 1 & 0 & 1 & 0 & 1 & 1 \\
\hline MiG-23 U & 0 & 1 & 0 & 1 & 0 & 2 & 2 \\
\hline $\begin{array}{c}\text { Total for } \\
\text { aircraft type }\end{array}$ & $\begin{array}{c}1 \\
(16.7 \%)\end{array}$ & $\begin{array}{c}5 \\
(83.3 \%)\end{array}$ & $\begin{array}{c}0 \\
(0 \%)\end{array}$ & $\begin{array}{c}6 \\
(100 \%)\end{array}$ & $\begin{array}{c}1 \\
(16.7 \%)\end{array}$ & $\begin{array}{c}6 \\
(83.3 \%)\end{array}$ & $\begin{array}{c}7 \\
(100 \%)\end{array}$ \\
\hline \multicolumn{8}{|l|}{ L-29 } \\
\hline L-29 & 1 & 4 & 0 & 5 & 1 & 4 & 5 \\
\hline $\begin{array}{c}\text { Total for } \\
\text { aircraft type }\end{array}$ & $\begin{array}{c}1 \\
(20.0 \%) \\
\end{array}$ & $\begin{array}{c}4 \\
(80.0 \%) \\
\end{array}$ & $\begin{array}{c}0 \\
(0 \%) \\
\end{array}$ & $\begin{array}{c}5 \\
(100 \%)\end{array}$ & $\begin{array}{c}1 \\
(20.0 \%)\end{array}$ & $\begin{array}{c}4 \\
(80.0 \%)\end{array}$ & $\begin{array}{c}5 \\
(100 \%)\end{array}$ \\
\hline \multicolumn{8}{|l|}{ Su-22 } \\
\hline Su-22 M-4 & 1 & 2 & 0 & 3 & 1 & 2 & 3 \\
\hline $\begin{array}{c}\text { Total for } \\
\text { aircraft type }\end{array}$ & $\begin{array}{c}1 \\
(33.3 \%) \\
\end{array}$ & $\begin{array}{c}2 \\
(66.7 \%) \\
\end{array}$ & $\begin{array}{c}0 \\
(0 \%) \\
\end{array}$ & $\begin{array}{c}3 \\
(100 \%) \\
\end{array}$ & $\begin{array}{c}1 \\
(33.3 \%) \\
\end{array}$ & $\begin{array}{c}2 \\
(66.7 \%) \\
\end{array}$ & $\begin{array}{c}3 \\
(100 \%) \\
\end{array}$ \\
\hline \multicolumn{8}{|l|}{ II-28 } \\
\hline Il-28 & 1 & 0 & 0 & 1 & 0 & 1 & 1 \\
\hline $\begin{array}{c}\text { Total for } \\
\text { aircraft type }\end{array}$ & $\begin{array}{c}1 \\
(100 \%)\end{array}$ & $\begin{array}{c}0 \\
(0 \%)\end{array}$ & $\begin{array}{c}0 \\
(0 \%)\end{array}$ & $\begin{array}{c}1 \\
(100 \%)\end{array}$ & $\begin{array}{c}0 \\
(0 \%)\end{array}$ & $\begin{array}{c}1 \\
(100 \%)\end{array}$ & $\begin{array}{c}1 \\
(100 \%)\end{array}$ \\
\hline $\begin{array}{c}\text { Total for all } \\
\text { aircraft types }\end{array}$ & $\begin{array}{c}38 \\
(18.2 \%)\end{array}$ & $\begin{array}{c}168 \\
(80.4 \%)\end{array}$ & $\begin{array}{c}3 \\
(1.4 \%)\end{array}$ & $\begin{array}{c}209 \\
(100 \%)\end{array}$ & $\begin{array}{c}37 \\
(16.2 \%)\end{array}$ & $\begin{array}{c}191 \\
(83.8 \%)\end{array}$ & $\begin{array}{c}228 \\
(100 \%)\end{array}$ \\
\hline
\end{tabular}



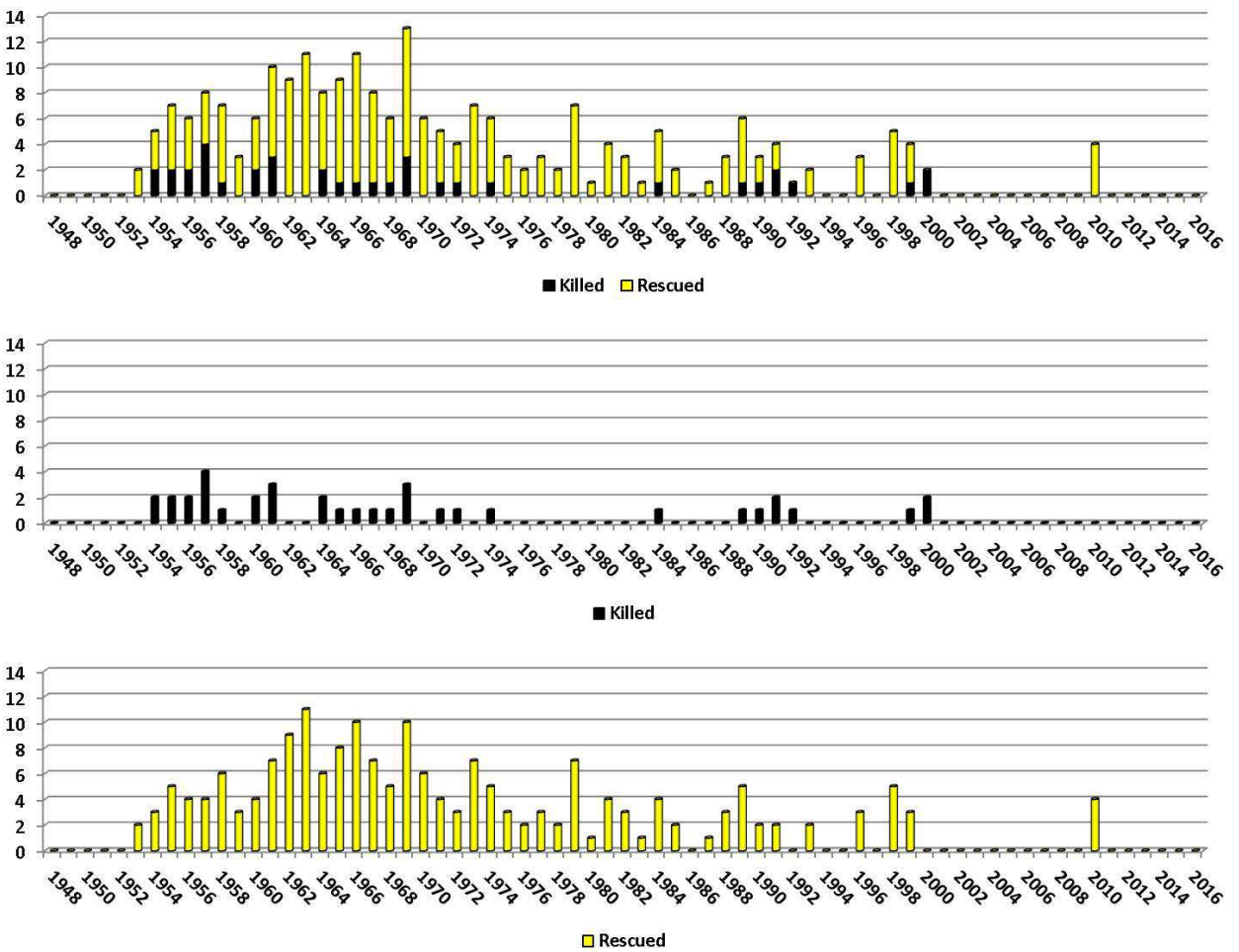

Fig. 5 Graphical overview of total and partial numbers of killed and rescued aircraft crew members in 1948-2016 [1-17]

introduction of Yak-23s and MiG-15s, the first jet aircraft in Czechoslovakia equipped with ejection seats. This was preceded by approximately ten air disasters with no attempts to eject.

If we put into a ratio the total number of successfully ejected (rescued) crew members with the total number of unsuccessfully ejected (killed) crew members, we obtain the number of rescued crew members per one crew member killed. The most favorable results were found for the Su-7 (23 rescued per 1 killed), MiG-21 (approx. 8 rescued per 1 killed) and MiG-23 (approx. 6 rescued per 1 killed). The most unfavorable results were found for the Su-22 (2 rescued per 1 killed) and L-39 and MiG-15 (approx. 3 rescued per 1 killed).

It should be noted that Tab. 1 shows the sum of successful ejections, i.e. the sum of ejected crew members rescued in AAs recorded as both air crash and damage without deducting 5 duplicate cases, since five pilots ejected two times during their active aviation service, even in different types of aircraft.

If we want to establish accurately the number of rescued persons, we must deduct those 5 cases from the total of 191 successful ejections. In this way, we arrive at 186 human lives saved by an aircraft ejection seat. 


\section{Conclusion}

The statistical overviews show that AAs associated with aircraft crew ejections can be seen as one of the key indicators of flight safety. It is, however, necessary to put the figures into appropriate contexts with other important technical, political and military-strategic factors in the periods in question.

The facts summarized in the following paragraphs can be concluded from the statistics of ejections:

A. From a long-term perspective, the number of AAs, and thus the number of ejections, has been on the decline.

The reason for this is the fact that the number of aircraft in active service, and thus also the flight hours, has been decreasing over time, while the quality of aircraft and the overall level of flight safety have been gradually increasing. The number of aircraft in active service has fallen from the original several thousand in the 1950s and 1960s to several hundred in the 1970s and 1980s and finally to a few dozens in the 1990s until present. In the 1950s, there were about 130000 flight hours for the entire Air Force per year; at present there are about 13000 flight hours per year. The changes in numbers and in the structure of the military aviation are also determined by its primary tasks, which have also changed over time with the evolution of the political situation in Europe.

B. From a long-term perspective, the number of ejection attempts in AAs has increased.

This fact testifies to the progress in aircraft crew training. In general, it took about 20 years from the introduction of military jet aircraft in the Czechoslovak Air Forces to overcome major difficulties associated with the operation of this aviation technology in terms of both technical and human factors. This is evidenced, inter alia, by the content and quality of service regulations and by the structure of the causes of AAs in that period.

C. The number of AAs in which the crew ejected successfully (survived) has been increasing.

This fact again testifies not only to the major progress in the training of crews but also to the positive technical development of onboard rescue systems.

D. There are differences between the number of both AAs and ejections in different types of aircraft.

These differences are usually due not only to the number of aircraft of a specific type, the number of years in active service (including corresponding flight hours) or to the predestination of those aircraft, but also to the crew training standards and, in particular, to in which period the aircraft were operated.

This study on the statistics of AAs associated with aircraft crew ejections points out interesting facts of the past and present that can be further analyzed to contribute to the current flight safety. The above analyses can be expanded by an analysis of causes of AAs associated with ejections, a review of development trends in ejection seats or by an analysis of injuries to the crew members resulting from ejections, for example.

The main objective of this type of analyses is always the high effectiveness of work, health protection and safety of the aircraft crews in the exercise of their demanding profession in service to the country. 
The author would like to give thanks to all members of ejected crews and other specialists who were willing to share their knowledge of aircraft rescue systems and their experience with ejections in favor of a safer future of military flying. Their work, personal commitment and strong will to survive in desperate situations deserves our respect and respect of future generations, in whose favor their pass on their experience.

\section{Acknowledgement}

The author would like to thank Lt. Col. (Ret.) Miroslav Němec, Lt. Col. Radim Buchta, Lt. Col. Pavel Štrůbl, Lt. Col. Karel Valvoda, Mr. Libor Režňák, Mr. Miroslav Irra, Col. Petr Chamrad, Lt. Col. (Ret.) Emil Padiora, Lt. Col. (Ret.) František Pisch for their help in tracing the statistics of aviation accidents and their helpful counsel and to all others who contributed to this study with their valuable advice and experience.

This study has been supported by the project: SP2018/152 - Developments in flight safety of military jet aircraft in conjunction with fire occurrence and aircraft crew ejection during flights.

\section{References}

[1] IRRA, M. Aero Avia S/CS-92 (in Czech). Nevojice: Jakab, 2014. ISBN 978-8087350-17-1.

[2] IRRA, M. MiG-15: Vol. 3. [Bi-lingual English/Czech publication]. Nevojice: Jakab, 2007, 96 p. ISBN 978-80-87161-01-2.

[3] IRRA, M. MiG-17: The "Seventeen" [Bi-lingual English/Czech publication]. Nevojice: Jakab, 2012, 128 p. ISBN 978-80-87350-10-2.

[4] IRRA, M. Ilyushin Il-28: The Ilyushin Il-28 in Czechoslovak Air Force [Bilingual English/Czech publication]. Nevojice: Jakab, 2013, 128 p. ISBN 978-8087350-12-6.

[5] IRRA, M. The Mikoyan-Gurevich MiG-19 in Czechoslovak Air Force (in Czech). Nevojice: Jakab, 2014, 128 p. ISBN 978-80-87350-15-7.

[6] IRRA, M. The "Twenty-one": The MiG-21 in Czechoslovak and Czech Air Force 1962-2005: Vol. 2. [Bi-lingual English/Czech publication]. Nevojice: Jakab, 2008, 112 p. ISBN 978-80-87161-04-3.

[7] IRRA, M. Aero L-29 “Dolphin”: Vol. 2 (in Czech). Nevojice: Jakab, 2016. ISBN 978-80-87350-34-8.

[8] REŽŇÁK, L. The Silver Jet MiG-15: Jet Beginnings of the Czechoslovak Air Force 1950-1957 (in Czech). Cheb: Svět křídel, 2012, 567 p. ISBN 978-8087567-14-2.

[9] REŽŇÁK, Libor. The Steel Stallion MiG-19 and the Czechoslovak Air Force 1958-1972 (in Czech). Cheb: Svět křídel, 2008, 582 s. ISBN 978-80-86808-45-1.

[10] Military Central Archives: Homepage. Military Central Archives: Homepage [on-line]. Praha, 2010 [cited 2018-03-10]. Available from: <http://www. vuapraha.cz/>. 
[11] SLAVÍK, S. Overview of Aviation Accidents, Serious Preconditions and Preventive Experience (Book 1) (in Czech). Hradec Králové, 1979.

[12] SLAVÍK, S. Overview of Aviation Accidents, Serious Preconditions and Preventive Experience (Book 2) (in Czech). Hradec Králové, 1979.

[13] SLAVÍK, S. Overview of Aviation Accidents, Serious Preconditions and Preventive Experience (Book 3) (in Czech). Hradec Králové, 1981.

[14] SLAVÍK, S. Overview of Aviation Accidents, Preconditions and Preventive Experience 1981-1982 (in Czech). Hradec Králové, 1986.

[15] SLAVÍK, S. Overview of Aviation Accidents, Preconditions, Deficiencies and Preventive Experience 1983-84 (in Czech). Hradec Králové, 1989.

[16] AURA, Inc. Information System for Logistics of Ministry of Defence and the Army of the Czech Republic (ISL) [software].

[17] Military Central Archives: Administrative Archives of the Armed Forces of the Czech Republic. Military Central Archives: Administrative Archives of the Armed Forces of the Czech Republic [on-line]. Prague, 2010 [cited 2018-03-10]. Available from: http://www.vuapraha.cz/archiv-ACR

[18] Flight Safety [regulation Všeob-P-10] (in Czech). Prague: Ministry of Defense, 2006.

[19] Ministry of Defence of the Czech Republic. Flight Safety [Order of the Minister of Defence No. 13/2006 of the Journal]. Prague: Ministry of Defence, 2016. 